\title{
An Investigation of English Usage in Careers of Thai Graduates with a Business Administration Degree
}

\section{OPEN ACCESS}

Manuscript ID:

EDU-2020-09013416

Volume: 9

Issue: 1

Month: December

Year: 2020

P-ISSN: 2320-2653

E-ISSN: 2582-1334

Received: 01.09.2020

Accepted: 20.10.2020

Published: 01.12.2020

Citation:

Low, Piyada. "An

Investigation of English

Usage in Careers of Thai

Graduates with a Business

Administration Degree.”

Shanlax International

Journal of Education, vol. 9 , no. 1,2020 ,

pp. 27-32.

DOI:

https://doi.org/10.34293/

education.v9i1.3416

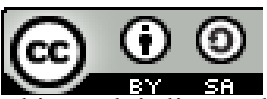

This work is licensed under a Creative Commons Attribution-ShareAlike 4.0 International License

\author{
Piyada Low \\ Assistant Professor, Faculty of Management Sciences, Kasetsart University, Bangkok, Thailand \\ https://orcid.org/0000-0002-4274-9031
}

\begin{abstract}
The research study aims to investigate English usage in careers of graduates with business administration degree in seven fields of study: Finance, Management, Marketing, International Business, Hotel and Tourism Management, Managerial Accounting, and Logistics Management. Google apps, Facebook, and LINE were the main instruments to collect the data. The questionnaire was created in a Google Form, then, was distributed and shared via Facebook, Facebook messenger, and LINE. Data were analyzed in the forms of graph, chart and percentages by using Google Data Studio. SPSS was also employed to interpret the 5 rating scale questions. The number of respondents was $221.41 .6 \%$ of the respondents were 22 years old and they were fresh graduates. Level of English usage in the workplace was high $(M=3.57)$ especially reading skill $(M=3.63)$. English speaking was mentioned as the most useful course at work. English for Specific Purposes (ESP) courses were mentioned in particular careers. Graduates in Managerial Accounting mentioned English for Accountant I and II while graduates in Hotel and Tourism Management mentioned Technical English for Hotel Business, Technical English for Tourism Business, and English for Food and Beverage Service. The most required training topic was English communication, followed by English speaking and English writing. The respondents also perceived that the English language was important for career advancement $(M=3.92)$.
\end{abstract}

Keywords: English usage in careers, English for specific purposes, Bachelor of Business Administration

\section{Introduction}

English is a compulsory foreign language in schools in Thailand. It is the language that Thai people use to communicate with foreigners. Moreover, English is one of a must in 'Qualifications' part of various job positions in different sectors. High proficiency in spoken and written English is regarded as the principal prerequisite qualification (Yimon, 2014; Rao, 2016). Therefore, English is important and enhances employability (Roshid \& Chowdhury, 2013; Wijiewardene et al., 2014; Yimon, 2014; Sankar \& Kumar, 2016; Rao, 2016; Durga, 2018).

From the 9th edition of the EP's English Proficiency Index (EP EPI, 2019), Thailand is in 74th place non-native speakers indicating very low proficiency. Rao (2016) pointed out that low proficiency in English or lack of English language skills was a barrier to academic success, entry of employment, and workforce accomplishment. He also emphasized that English proficiency was a key factor for employment success.

For Sankar \& Kumar (2016), English has become the language of business. It is the language of the information mostly found $(80 \%)$ on the internetcommunicating across the world. English is needed to run a smooth business and to deal with customers. English, therefore, is a medium to ensure employability (Roshid \& Chowdhury, 2013; Wijewardene et al., 2014; Sankar \& Kumar, 2016). Wijewardene et al. (2014) pointed out that the 21 st-century 
graduates should be work-ready with interpersonal skills, teamwork, oral and written English skills. Graduates without English competency will have hard time finding suitable employment. Roshid\& Chowdhury (2013) mentioned that English language fluency was associated with a higher salary while a lack of proficiency in English works as an obstacle to the employment market and a disadvantage in careers (Yimon, 2014).

The research study aims to investigate English usage in the careers of graduates from the Faculty of Management Sciences, Kasetsart University. Data from the study will be useful for planning and outlining English language courses at the Faculty of Management Sciences, Kasetsart University Sri Racha Campus.

\section{Research Objectives}

1. To investigate the English usage of graduates with a business administration degree from the Faculty of Management Sciences.

2. To investigate the topics of English training required by graduates of the Faculty of Management Sciences.

\section{Literature Review}

Research studies on English usage in careers have been conducted in different sectors in Thailand. All four language skills were mentioned as important at work (Numbenjapol, 1996; Yimon, 2014) though listening and speaking skills were most used in communicating with foreign customers in the hotel business (Low \& Pongsukvajchakul, 2014; Pandumrongsathi, 2013).

Thai graduates in Bangkok mentioned English as moderately high used in careers and the tendency of the use of English at work was at a high level (Yimon, 2014). Moreover, Thai graduates in the business sector mentioned that English skills of reading and translating were mainly used at work (Numbenjapol, 1996). Reading skill increased general and jobrelated knowledge while translating skills was to report information to colleagues or superiors.

Reading skill was confirmed as most used at work by Thai engineers in managing a Japanese company (Kosashunhanan, 2016) as they had to read e-mails and information on the Internet. The skill was also mentioned as needed by 30 customer support staff in the production office of an electronics manufacturer, EM (Thailand). The managers also agreed that reading skills was the most needed skill for their staff (Chaiyasit \& Thummawongsa, 2017).

Lack of English vocabulary knowledge was a serious problem to communicate at work (Low \& Pongsukvajchakul, 2014; Pandumrongsathi, 2013; Kosashunhanan, 2016; Yomyao, 2018). English training on-site, therefore, was preferred regularly (Low \& Pongsukvajchakul, 2014; Pandumrongsathi, 2013). As for professional nurses (Yomyao, 2018), the listening skill was the most serious problem and speaking skill was the most needed skill.

\section{Research Methods}

The study started with an online questionnaire in Google Form. The questionnaire was sent and shared by application programs: Facebook, Facebook messenger, and LINE.

\section{Subjects}

Subjects of the study were all graduates of the Faculty of Management Sciences with a Bachelor of Business Administration in 7 fields of study: Finance, Management, Marketing, International Business, Hotel and Tourism Management, Managerial Accounting, and Logistics Management.

\section{Instruments}

The research study employed Google, Facebook, Facebook messenger, and LINE programs. SPSS program was also used to interpret the data.

Facebook is a social networking website. It was the most popular social networking applications in Thailand or 28 million users in 2014 (Raphiphan, 2014), and Facebook Messenger was the second leading app used in 49 countries (Schwartz, 2016).

LINE is a mobile messaging service. It is widely used in Thailand and makes Thailand the second-largest market in the world after Japan (Phoosuphanusorn, 2017).

Google is a free web-based program. The vital role is to facilitate work performance on mobile devices (Al-Emran \& Malik, 2016). Google Forms is a free online survey application. For Haddad \& Youakim (2014), Google Forms is a very simple, 
systematic, and easy to implement the approach. Vasantha Raju \& Harinarayana (2016) pointed out that the anywhere-anytime-access and unlimited surveys of $100 \%$ free have made Google Forms a popular product in online survey research. For Google Data Studio, the application helps visualize data with adjusted color and style options of charts and tables.

The research study used Google Form to create an online questionnaire and distributed via Facebook, Facebook Messenger, and LINE. The questionnaire consisted of three parts. The first part required personal and career information. The second part consisted of 10 questions about English usage and English language skills in careers with 5 rating scales from 1 to 5 . The third part was for opinions on useful English language courses and the required topics on English training in careers. Google Data Studio and SPSS were employed to report the collected data.

\section{Data Analysis}

The data were analyzed in the forms of charts and graphs with percentages. Google spreadsheet, then, was created and exported into Microsoft Excel format to be analyzed by Google Data Studio and SPSS. General background of the subjects, factors affecting English usage in careers and opinions on English usage and training topics were described in percentages.

\section{Findings}

The total number of respondents was 221: 177 females $(80.5 \%), 43$ males $(19.5 \%)$, and 1 person without an answer on sex. The youngest respondent was 21 years old, while the oldest respondent was 33 years old. $41.6 \%$ of the respondents were 22 years old and they were fresh graduates. Figure 1 shows the age range of the respondents.

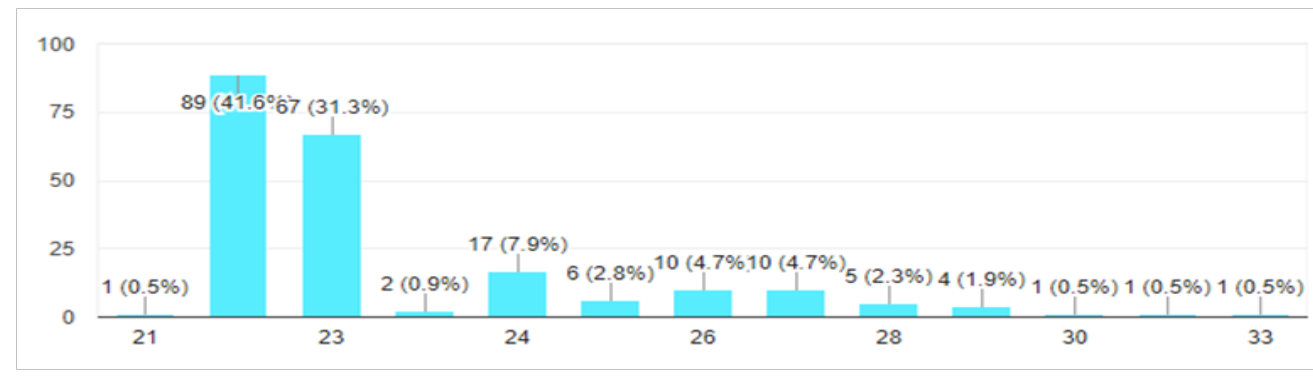

Figure 1: Age range of the respondents

Respondents in Managerial Accounting (26.4\%) and Tourism Management (25.5\%). Respondents in were the most followed by respondents in Hotel Marketing ( 2 respondents) were the least.
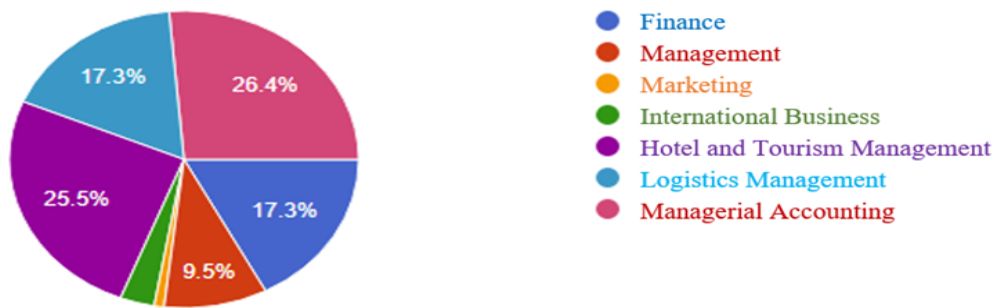

Figure 2: Respondents from the seven fields of study

There were 111 respondents working for Thai organizations, 53 respondents in international organizations, 48 respondents in foreign private organizations, and 9 respondents without work type indications. In terms of the workplace, Bangkok was the place where most of the respondents worked (56.9\%), followed by Chonburi (16.1\%) which is the province where Kasetsart University Sri Racha Campus is situated.

For the working department section, auditing (16.675) and accounting (9.8\%) were indicated most by the respondents. Though Marketing was the field of study with the least response, the sales and marketing department was mentioned by 11 
respondents from respondents in other fields of study.

Although there were 221 respondents, only 217 respondents rated the 5 rating scale questions on levels of English usage and skills in the workplace and questions on English communication and English usage in the workplace. The respondents rated the level of English usage in the workplace as high $(\mathrm{M}=3.57)$, especially reading skills $(\mathrm{M}=3.63)$.

Table 1: Level of English usage and Language Skills in the Workplace

\begin{tabular}{|c|c|c|c|c|c|}
\hline & \multicolumn{2}{|c|}{$\mathbf{n}$} & \multirow{2}{*}{$\mathbf{M}$} & \multirow{2}{*}{ Std. Error of $M$} & \multirow{2}{*}{ SD } \\
\hline & Valid & Missing & & & \\
\hline Level of English usage in the workplace & 217 & 3 & 3.57 & .068 & 1.007 \\
\hline Listening skill in the workplace & 217 & 3 & 3.25 & .074 & 1.091 \\
\hline Speaking skill in the workplace & 217 & 3 & 3.10 & .077 & 1.138 \\
\hline Reading skill in the workplace & 216 & 4 & 3.63 & .072 & 1.052 \\
\hline Writing skill in the workplace & 217 & 3 & 3.38 & .080 & 1.177 \\
\hline
\end{tabular}

English usage on documents was mentioned advancement $(\mathrm{M}=3.92)$. Table 2 shows English as high $(\mathrm{M}=3.65)$. The respondents perceived that communication and English usage in the workplace. the English language was important for career

Table 2: English Communication and English usage in the Workplace

\begin{tabular}{|l|c|c|c|c|c|}
\hline \multirow{2}{*}{} & \multicolumn{2}{|c|}{$\mathbf{n}$} & \multirow{2}{*}{ M } & \multirow{2}{*}{ Std. Error of M } & SD \\
\cline { 2 - 4 } & Valid & Missing & & & .081 \\
\hline English communication with customers organizations & 216 & 4 & 3.24 & .195 \\
\hline English usage on documents & 217 & 3 & 3.65 & .079 & 1.156 \\
\hline English usage in meeting & 217 & 3 & 2.80 & .084 & 1.234 \\
\hline English usage in job presentation & 217 & 3 & 2.79 & .086 & 1.272 \\
\hline English language and career advancement & 217 & 3 & 3.92 & .078 & 1.148 \\
\hline
\end{tabular}

Two open-ended questions were employed for the graduates to express their opinions on useful English language courses and the required topics on English training in careers.

1. Which English courses are useful for you? Why?

2. What topics should be in English training for careers?

There were 175 answers for the first question. English speaking course was mentioned as the most useful (by 32 respondents) followed by Speech Communication course (by 24 respondents). They mentioned that the speaking course and speech communication course helped communicate with their colleagues, supervisors, and department heads. Eighteen respondents mentioned that all English courses were important and useful for them. However, English for Specific Purposes (ESP) courses were also highly useful in their careers. Graduates in Managerial Accounting major mentioned English for Accountant I, II (by 20 respondents) while graduates in Hotel and Tourism Management mentioned three ESP courses: Technical English for Hotel Business (by 12 respondents), English for Food and Beverage Service (by 3 respondents), and Technical English for Tourism Business (by 3 respondents).

There were 166 answers to the second question. English communication was the topic mentioned most (by 45 respondents), followed by speaking (by 26 respondents) and writing (by 20 respondents). Other required topics were English for presentation (by 12 respondents), English for a job interview (by 10 respondents), E-mail writing (by 6 respondents) and formal English language (by 3 respondents).

\section{Discussion and Conclusion}

The finding that $41.6 \%$ of the respondents were fresh graduates was not a surprise as they still had close contacts with lecturers who helped share the online questionnaire. 
The finding that auditing (16.675) and accounting (9.8\%) were indicated most as the working departments of the respondents was in line with the fact that most respondents were in Managerial Accounting major (26.4\%).

Reading skill was mentioned as high $(\mathrm{M}=3.63)$. The finding confirmed the importance of reading skills as found in previous studies (Numbenjapol, 1996; Kosashunhanan, 2016; Chaiyasit \& Thummawongsa, 2017). The skill was related to English usage on documents which was also high ( $\mathrm{M}=$ 3.65). Other required English training topics were E-mail writing and formal English language. These mentioned courses will enhance job performance, job satisfaction, and career development(Yomyao, 2018).

Apart from general English courses, ESP courses were mentioned. These ESP courses are compulsory courses for the related fields of study. English for Accountant I, II was mentioned because most respondents were graduates in Managerial Accounting (26.4\%). Three ESP courses for Hotel and Tourism Management major were also mentioned as $25.5 \%$ of the respondents were graduates in Hotel and Tourism Management. These courses which focus on English communication skills in particular professional fields, enable graduates of the faculty to master relevant English communication and professional skills in the workplace. Formal English language and English vocabulary in specific business situations are needed in outlining the course syllabuses. The findings help implement and develop English courses to enhance the English proficiency of future graduates.

\section{References}

Al-Emran, Mostafa, and Sohail Iqbal Malik. "The Impact of Google Apps at Work: Higher Educational Perspective." International Journal of Interactive Mobile Technologies, vol. 10, no. 4, 2016, pp. 85-88.

Chaiyasit, Sattawat, and Narathip Thummawongsa. "A Study of Needs of Staff's English Communication Skills: A Case Study of an Electronic Company (Computer Parts)." International Journal of Management and Applied Science, vol. 3, 2017, pp. 88-91.
Durga, V Satya Sri. "The Need of English Language Skills for Employment Opportunities." Journal of Research Scholars and Professionals of English Language Teaching, vol. 2, no. 7, 2018.

EF English Proficiency Index, Education First, 2019, https://www.ef.com/_/ / /media/ centralefcom/epi/downloads/full-reports/v9/ ef-epi-2019-english.pdf

Haddad, Rami J., and Youakim Kalaami. "Google Forms: A Real-Time Formative Assessment Approach for Adaptive Learning." Proceedings of the 2014 American Society for Engineering Education, 2014.

http://www.it24hrs.com/2014/thai-socialnetwork-2014/

Joseph. "The Most Popular Messaging App in Every Country." Similar Web, 2016.

Kosashunhanan, Krishan. "The Use of English for Communication by Thai Engineers: Case Study of Japanese Companies at Amata Nakorn Industrial Estate." Suthiparithat Journal, vol. 30, no. 93, 2016, pp. 146-159.

Low, Piyada, and Patsara Pongsukvajchakul. "Front Desk Skills Development: English Usages, Problems, and Needs." Humanities and Social Sciences Review, vol. 3, no. 4, 2014, pp. 223-231

Numbenjapol, P. "Usage of English in Business and English Language Proficiency Levels of Kasetsart University Graduates Employed in Business Sector." Kasetsart Journal of Social Sciences, vol. 17, 1996, pp. 149-159.

Pandumrongsathit, S. "Needs of English using for staff in Hotel Business Enterprises in Pahtumthani Province." Pathumthani University Academic Journal, vol. 5, no. 1, 2013, pp. 29-38.

Phoosuphanusorn, S. "Next in Line." Bangkok Post, 2017, https://www.bangkokpost.com/ tech/1204673/next-in-line

Rao, Chandra Sekhar. "A Brief Study of English Language Proficiency: Employability." English for Specific Purposes World, vol. 17, 2016.

Roshid, Mohammod Moninoor, and Raqib Chowdhury. "English Language Proficiency 
and Employment: A Case Study of Wijewardene, Lishanthi, et al. "English for Bangladeshi Graduates in Australian Employability - The Need of the Hour for Employment Market." Mevlana International Journal of Education, vol. 3, no. 1, 2013, pp. 68-81.

Sankar, G., and S.P. Suresh Kumar. "English for Employability and Empowerment - A Study." International Journal of English Literature and Culture, vol. 4, no. 6, 2016, pp. 100-103.

Vasantha Raju, N., and N.S. Harinarayana. "Online Survey Tools: A Case Study of Google Forms." National Conference on Scientific, Computational \& Information Research Trends in Engineering, 2016.

Sri Lankan Graduates." British Journal of Arts and Social Sciences, vol. 17, no. 1, 2014, pp. 137-145.

Yim-on, Yaowalak. "The Use of English in the Careers of Thai Graduates in Bangkok." Panyapiwat Journal, vol. 5, no. 2, 2014, pp. 191-204.

Yomyao, A. "The Essential English Skills using Problem for Professional Nurses Working in the Medium and the Large Hospitals in Chiang Rai Province." Private Higher Education Institutions Association, vol. 23, no. 2, 2018, pp. 56-66.

\section{Author Details}

Piyada Low, Assistant Professor, Faculty of Management Sciences, Kasetsart University, Bangkok, Thailand,

Email ID: fmspyl@ku.ac.th. 